\title{
Proteinuria Severity in Lupus Nephritis is Associated with Anti-dsDNA Level and Immune Complex Deposit Location in Kidney
}

\author{
Katherina Alfa Engli 1,2*, Kusworini Handono 1,2 , Mudjiwijono Handaru Eko 2, 3 , Hani Susianti ${ }^{1,2}$, \\ Atma Gunawan 2, 4 , Handono Kalim 2, 4 \\ ${ }^{1}$ Department of Clinical Pathology, Faculty of Medicine, Brawijaya University, Malang 65145, Indonesia \\ ${ }^{2}$ dr. Saiful Anwar Public Hospital, Malang 65112, Indonesia \\ ${ }^{3}$ Department of Anatomical Pathology, Faculty of Medicine, Brawijaya University, Malang 65145, Indonesia \\ ${ }^{4}$ Department of Internal Medicine, Faculty of Medicine, Brawijaya University, Malang 65145, Indonesia
}

Article history:

Submission March 2018

Revised May 2018

Accepted July 2018

*Corresponding author:

E-mail:

katherinengli78@gmail.com

\begin{abstract}
Lupus nephritis (LN) is one of the manifestations of Systemic Lupus Erythematosus (SLE), with proteinuria being one of the clinical manifestations. The proteinuria pathogenesis is associated with anti-dsDNA antibody and the location of immune complex deposits within the kidney. This study aims to investigate the correlation of the severity of proteinuria with the location of immune complex deposits and the level of antidsDNA antibody in LN. Data were collected in cross-section. Fifty-three patients with LN in Saiful Anwar Hospital Malang, who underwent renal biopsy, were included. Hematoxylin-eosin staining and immunofluorescence analysis were used to assign subjects to different histopathological classes and determine the immune complex deposits. The spot urine samples were evaluated using the dipstick method for semiquantitative proteinuria. The anti-dsDNA antibody levels were evaluated using the enzyme-linked immunosorbent assay (ELISA). Turbidity and enzymatic tests were conducted to elucidate urine protein and creatinine content, respectively. The level of proteinuria is significantly different among the different locations of immune complex based on the dipstick and protein/creatinine methods ( $p=0.021$ and $p=0.005$, respectively). There was a significant correlation between anti-dsDNA antibody level and the severity of proteinuria $(r=0.326$ based on dipstick and $r=0.28$ based on protein/creatinine method). Thus, proteinuria in LN is determined by anti-dsDNA level and the location of immune complex deposits in the kidney.
\end{abstract}

Keywords: anti-dsDNA, immune complex, lupus nephritis, proteinuria

\section{Introduction}

Systemic Lupus Erythematosus (SLE) is an autoimmune disease involving many organ systems, including the kidney, skin, lung, heart, blood, and brain, characterized by autoantibody and immune complex deposition causing tissue damage [1, 2]. SLE can affect all age groups, but mostly affects people of reproductive age, between 15 and 40 years old [3]. The annual incidence of SLE in America is 5.1 per 100,000, while the prevalence of SLE is 52 cases per 100,000 populations [4]. The frequency is higher in females compared to males, with the ratio of $9-14$
: 1. There are no epidemiological data of SLE which include all areas of Indonesia. Data from RSUP Cipto Mangunkusumo (RSCM) Jakarta in 2012 showed that $1.4 \%$ of all patient visits in the Rheumatology Polyclinic of the Internal Medicine Department was SLE cases, while there were 291 SLE patients or approximately $10.5 \%$ of all patients visiting the Rheumatology Polyclinic in Hasan Sadikin Bandung Hospital during 2010 [5].

SLE has many clinical manifestations; one of the most serious manifestations, involving the kidney, is known as lupus nephritis (LN). Patients with SLE show abnormal urinalysis results or re-

\section{How to cite:}

Engli KA, Handono K, Eko MH et al. (2018) Proteinuria Severity in Lupus Nephritis is Associated with Anti-dsDNA Level and Immune Complex Deposit Location in Kidney. Journal of Tropical Life Science 8 (3): 217 - 226. doi: 
nal dysfunction of about $25-50 \%$ in the beginning of the disease. This can increase to $60 \%$ in adult patients, developing into chronic kidney disease and end-stage renal disease (ESRD) in at least 5 years [6]. The United States Renal Data Service noted that the incidence of ESRD caused by LN in 1996-2004 was 4.5 cases per 1 million populations [7]. LN is more commonly found in people of Asian and African ethnicity; these groups also have a worse prognosis compared to other races [6]. The frequency of LN in Malang is relatively high. A study by Handono of 31 SLE patients who underwent renal biopsy showed that $58 \%$ of patients had LN with a poor prognosis, LN class III, $\mathrm{IV}$, and $\mathrm{V}$, which mostly end in renal failure. The study mentioned that $37.5 \%$ of the 8 patients with normal laboratory results had a histopathological classification of LN class III and IV [8].

The presentation of renal disorder in $\mathrm{LN}$ can be divided into nephritic and nephrotic presentations based on clinical manifestations and laboratory studies. The difference in pathological processes of both presentations is not clearly understood. The clinical manifestation of this disorder is related to the immune complex deposits located in the kidney and the type of immunoglobulin (Ig) involved, presumably as the trigger of inflammation [9].

The recent opinion states that the location of immune complex deposits is one of the causes of the differences in the nephritic and nephrotic manifestations of LN. Immune complex deposits in subendothelial and mesangial regions will show a nephritic appearance. Histopathologically, it shows a mesangial, focal and diffuses proliferative appearance, and clinically shows active urine sediment (erythrocyte, leukocyte, cylinder cell, and granules), mild proteinuria, and normal or slightly reduced renal function [10,11]. Immune complex deposits in the subepithelial region histopathologically show membranous nephropathy appearance and clinically induce symptoms of severe proteinuria $[9,11]$. This is probably because the subepithelial area does not relate to the blood vessels because it is separated by the basal membrane of the glomerulus [9]. Some cases have been reported with immune complex deposits in the mesangial region, which showed a nephrotic instead of a nephritic appearance [10]. A study by Han et al. also showed that the location of immune complex deposits had no relationship with the proteinuria in
LN [12].

The main immunological disorder in SLE is the autoreactive $\mathrm{T}$ and $\mathrm{B}$ cells producing many types of autoantibody $[13,14]$. One of the specific antibodies for SLE is the double-stranded deoxyribonucleic acid (anti-dsDNA) antibody, especially the IgG class, which is believed to play an important role in the pathogenesis of organ manifestations, especially glomerulonephritis [13, 15], it can also be found along with IgM and IgA [9, 16]. The autoimmune response of the dsDNA antibody is considered as the main mediator of the inflammatory response that leads to kidney damage $[14,17]$. Some studies show that anti-dsDNA antibodies and complement are useful in assessing the disease and renal activity $[14,18]$.

Generally, the assessment of renal activity in $\mathrm{LN}$ is based on the clinical variables of active urine sediment, amount of proteinuria, and a decrease in renal function $[18,19]$. Some studies suggest the significance of proteinuria in kidney damage pathogenesis [20]. Waldman and Madaio also Villalta et al. stated that there was an association between the titer of anti-dsDNA antibody and disease activity, and the anti-DNA antibody was found in immune deposits in the glomerulus of humans and rats with nephritis [14, 15]. Moroni et al. found that LN patients with high anti-dsDNA levels had significantly higher proteinuria compared to normal subjects [18]. As the matter of fact, the anti-dsDNA antibody and proteinuria severity can serve as diagnostic markers and help in assessing treatment's effectiveness [15, 21].

The arguments above illustrate the significance of the proteinuria and anti-dsDNA antibodies in the pathogenesis of kidney damage, but the association among these two markers in LN is not well understood yet. Therefore, this study tried to elucidate the association by comparing the antibody's quantity and deposit locations to proteinuria severity in LN patients. This study took urine and serum samples from patients who had undergone renal biopsy and examined the IgG of anti-dsDNA antibodies, as well as the histopathology of the immune complex deposits located in the kidney to understand the association with proteinuria severity.

\section{Material and Methods \\ Research design and ethical consideration}

This was an observational, cross-sectional stu- 
dy. The population studied was composed of SLE patients visiting the internal medicine polyclinic or inpatient division of the Department of Internal Medicine in Saiful Anwar Public Hospital, Malang. The study samples were SLE patients diagnosed with LN by rheumatology consultants based on the ARA 1997 criteria and the results of renal biopsy histopathology. The data in this study were taken between July 2012 and June 2014. This study was approved by the ethical committee of Faculty of Medicine, Brawijaya University and Saiful Anwar Public Hospital, Malang with approval number No.469/EC/KEPK/08/2014. The inclusion criteria of this study were patients diagnosed with LN, tissue samples from renal biopsy with more than 10 glomeruli, and the patient agrees to participate in this study, including signing the informed consent. The exclusion criteria were patients with the congenital renal disorder, frank infection (leukocyturia) during sampling, and diabetes mellitus. Sample size calculation was based on Dahlan's formulation in correlational observational study [22], detailed as follow:

$$
n=\left(\frac{Z_{\alpha}+Z_{\beta}}{0.5 \operatorname{Ln}((1+r) /(1-r))}\right)^{2}+3
$$

Note:

n : Minimum sample size

$\mathrm{Z} \alpha \quad$ : Normal distribution value ( $\mathrm{Z}$ table) in $\alpha$ value

$\mathrm{Z} \beta \quad$ : Normal distribution value ( $\mathrm{Z}$ table) in $\beta$ value

$\mathrm{r} \quad$ : Correlation value

for $Z_{\alpha}(5 \%)=1.645 ; Z_{\beta}(10 \%)=1.282$; and $r=$ 0.394 , the minimum sample size would be:

$$
n=\left(\frac{1.645+1.282}{0.5 \operatorname{Ln}((1+0.394) /(1-0.394))}\right)^{2}+3=52.38
$$

or rounded to 53 subjects in order to represent the population.

\section{Tissue sampling and preservation}

The renal biopsy was performed by a Renal and Hypertension Consultant Internist in the Department of Renal and Hypertension, Department of Internal Medicine, Saiful Anwar Public Hospital, Malang guided by ultrasonography (USG). Tissue sampling was undertaken twice. The tissue sample had to have at least 10 glomeruli. The first tissue sample was preserved in formalin 10\%, while the second was preserved using Optimum Cutting Temperature (OCT) compound. The renal tissue was sent to Laboratory of Anatomical Pathology immediately for embedding and paraffinization. Tissue cutting was performed with the thickness of $3.5 \mu \mathrm{m}$. The preparation was fixed on object glass and stained using immunofluorescence staining.

\section{Preparation and immunofluorescence staining}

The immune complex deposit location was the region in the glomerulus which had immune complex deposits stained with rabbit anti-human IgG/FITC polyclonal antibodies. Immunofluorescence staining was performed according to Bancroft and Gamble modifications, which state that the preparation was incubated at $37^{\circ} \mathrm{C}$ in an oven overnight. The preparation was then placed on a hot plate for 3 hours to maximize tissue adhesion to the object glass. Deparaffinization was performed using xylol I and II, each for 5 minutes. Samples were then dehydrated using absolute alcohol for 5 minutes, twice. After that, the preparation was dehydrated using $90 \%$ and $70 \%$ alcohol for 5 minutes each, and then soaked in $1 \mathrm{M}$ phosphate buffer saline (PBS) pH 7.43 times, for 5 minutes each, before it was soaked in $10 \mathrm{mM}$ citrate buffer pH 6 and heated in a high-temperature microwave for \pm 8 minute. The preparation was taken from the microwave, placed at room temperature, and then soaked 3 times for 5 minutes each. The preparation was dried of PBS residue and placed in a container layered with tissue paper and sprayed with water. Blotto solution (skim milk 2\%) was dropped onto the tissue and kept for 1 hour at room temperature. The preparation was then washed using PBS for 3 times, for 10 minutes each. PBS residue was dried and the antibody was prepared. Rabbit anti-human IgG/FITC polyclonal antibody (Fluorescein Isothiocyanate Isomer 1) (DAKO $\left.{ }^{\circledR}\right)$ was dissolved in skim milk with a ratio of $1: 1000$. The primary antibody solution was dropped onto the preparation and then incubated for 1 hour at room temperature. The preparation was washed with PBS 3 times, for 10 minutes each, and then the PBS residue was dried [23]. After that, the preparation was observed using an immunofluorescence microscope (FSX 100 Olympus ${ }^{\circledR}$ ), at a magnification of 400x. The location of immune complex deposits 
was evaluated by an anatomical pathology specialist.

\section{Anti-dsDNA assay}

The anti-dsDNA level was the level of antibody shown in the DNA. Anti-dsDNA antibody examination was performed using ELISA method (Cat\#2553Z, Diagnostic automation, Inc ${ }^{\circledR}$, Calabasas). The sample was serum taken right before the biopsy. The serum was collected and stored in $-80^{\circ} \mathrm{C}$ until the examination was done.

\section{Proteinuria examination}

Proteinuria was the protein level in urine. Proteinuria examination was done using a dipstick (Multistix ${ }^{\circledR}$ ) and urine protein/creatinine ratio calculation (UPCR). The sample used was urine taken immediately before the biopsy. The semiquantitative dipstick test results were: negative, $1^{+}, 2+$, and $3+$. The urine protein/creatinine ratio was determined by dividing the urine protein level (mg/dL) with urine creatinine (mg/dL). The results were reported in $\mathrm{mg} / \mathrm{mg}$. Dipstick method indicates the severity of proteinuria; negative indicates no observable proteinuria and 3+ indicates severe proteinuria. UPCR result indicates kidney damage. More than 0.5 protein/creatinine ratio indicates abnormalities in kidneys [24, 25]. Quantitative urine protein examination was performed using the turbidimetry method (Roche/Hitachi Cobas C 501). Urine creatinine examination was undertaken using the enzymatic colorimetry method (Roche/Hitachi Cobas C 501).

\section{Data analysis}

Data analysis was performed using SPSS 16.0 for Windows. Collected data would be tested by Kruskal-Wallis, Mann Whitney post hoc, and Spearman correlation tests. The results were significant if $\mathrm{p}<0.05$.

\section{Results and Discussion Subject characteristics}

Subject characteristics (Table 1) based on sex showed that the majority of patients were female, with a frequency of $94.3 \%$. The majority of LN patients were aged 26 to 35 years old (45.3\%). The most commonly found LN class was class III (37.7\%). The location of immune complex deposits was mostly in the mesangial, endothelial regions, accounting for $35.8 \%$. The results of prote-
Table 1. Subject characteristics

\begin{tabular}{lc}
\hline Variable & $\mathrm{n}(53)$ \\
\hline Sex & \\
\hline Male & $3(5.7 \%)$ \\
Female & $50(94.3 \%)$ \\
\hline Age (years old) & $1(1.9 \%)$ \\
\hline $6-15$ & $16(30.2 \%)$ \\
$16-25$ & $24(45.3 \%)$ \\
$26-35$ & $10(18.9 \%)$ \\
$36-45$ & $2(3.8 \%)$ \\
$46-55$ & \\
\hline LN Class & $3(5.7 \%)$ \\
\hline I & $15(28.3 \%)$ \\
II & $20(37.7 \%)$ \\
III & $7(13.2 \%)$ \\
IV & $8(15.1 \%)$ \\
IV and V & \\
\hline Location of immune complex deposit & $14(26.4 \%)$ \\
\hline Mesangial & $19(35.8 \%)$ \\
Mesangial, endothelial & $5(9.4 \%)$ \\
Mesangial, endothelial, epithelial & $10(18.9 \%)$ \\
Endothelial & $5(9.4 \%)$ \\
Endothelial, epithelial & \\
\hline Proteinuria** & $17(32.1 \%)$ \\
\hline Negative & $7(13.0 \%)$ \\
$1+$ & $14(26.4 \%)$ \\
$2+$ & $15(28.3 \%)$ \\
$3+$ & $3.03(0.06-$ \\
\hline Urine protein/creatinine ratio & $98.16) *$ \\
(mg/mg) & $93.0(10.90-$ \\
\hline Anti-dsDNA level (IU/mL) & $916.60) *$ \\
\hline &
\end{tabular}

Note: * Median (minimum-maximum)

** Proteinuria was measured using dipstick method: Negative result indicates no observable proteinuria while $3+$ indicates severe proteinuria, IU: International Unit, anti-dsDNA: antidouble-stranded Deoxyribonucleic Acid

inuria in LN patients examined with the dipstick test were mostly negative, accounting for $32.1 \%$. The ratio of urine protein/creatinine in LN patients had a median of $3.03 \mathrm{mg} / \mathrm{mg}$ which indicates abnormality in their kidney [25]. The anti-dsDNA level in $\mathrm{LN}$ patients had a median of $93.0 \mathrm{IU} / \mathrm{mL}$.

The results showed that the majority of research subjects were women and that the frequency of $\mathrm{LN}$ is higher in women than in men, with a ratio of $16.5: 1$. This frequency is much higher than that reported in the literature, which described an LN ratio for women to men of 10:1 [4] because SLE is found in women more often than in men. This is believed to be because the major hormone which plays a role in SLE is estrogen 
[26, 27]. In women, the metabolism of $17 \beta$-estradiol and estrone tends to produce 16-hydroxyestrone and estriol, which are substances that can stimulate mitosis, thus contributing to the occurrence of inflammation. The levels of these compounds may be higher in individuals with SLE than in healthy women [27].

The majority of patients in this study were within the reproductive age group ( 26 - 35 years). This is consistent with the statement that the SLE can occur in all age groups, with the most frequent incidence being for those of reproductive age, between 15 and 40 years [28, 29]. Similar results were shown by Walker, who stated that SLE tends to occur in women of childbearing age [27].

When stratified by $L N$ class, $37.7 \%$ of patients were LN Class III. This suggests that the LN prognosis in these patients tends to be bad. Handono showed that $58 \%$ of LN patients with poor prognosis have histopathological grade III, IV, or V [8]. Contreras et al. also showed a predominance of LN proliferation from $213 \mathrm{LN}$ patients, accounting for $30 \%$ of class III, $32 \%$ of class IV and $18 \%$ of class $\mathrm{V}$ patients [6].

\section{The Location of immune complex deposits and proteinuria}

This study found 5 groups of immune complexes deposit locations, which were mesangial; mesangial, endothelial; mesangial, endothelial, epithelial; endothelial; and endothelial, epithelial. Comparisons of the severity of proteinuria were performed. Proteinuria was measured using a dye test strip and the protein: creatinine urine ratio.

Kruskal-Wallis test analysis for proteinuria in LN patients with immune complex deposits in various locations showed a significant difference. The post hoc analysis Mann Whitney test showed a significant proteinuria difference in the location of immune complex deposits in the kidney $(\mathrm{p}<0.05)$. There was an observable trend that the location of immune complex deposit was increasing the more severe the proteinuria was (Figure 1). The data suggested that proteinuria severity may have association with the location of immune complex deposit. Interestingly, immune deposit also observed in the negative proteinuria.

The normality of the urine protein/creatinine ratio data was tested using the Kolmogorov-Smirnov test showed that the data did not have a normal distribution, even after data transformation; thus,

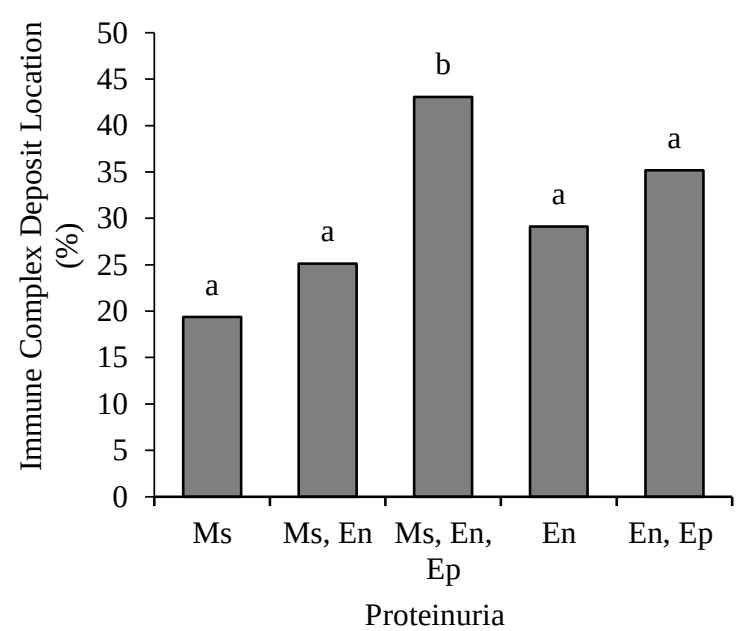

Figure 1. Differences between Immune Complex Deposit Location Group and Severity of Proteinuria. The different letter indicated the significantly differences between goups based on Mann-Whitney test. Note: Ms= Mesangial; En= Endothelial; Ep=Epithelial; Proteinuria was measured using dipstick test; ${ }^{*} \mathrm{p}<0.05$

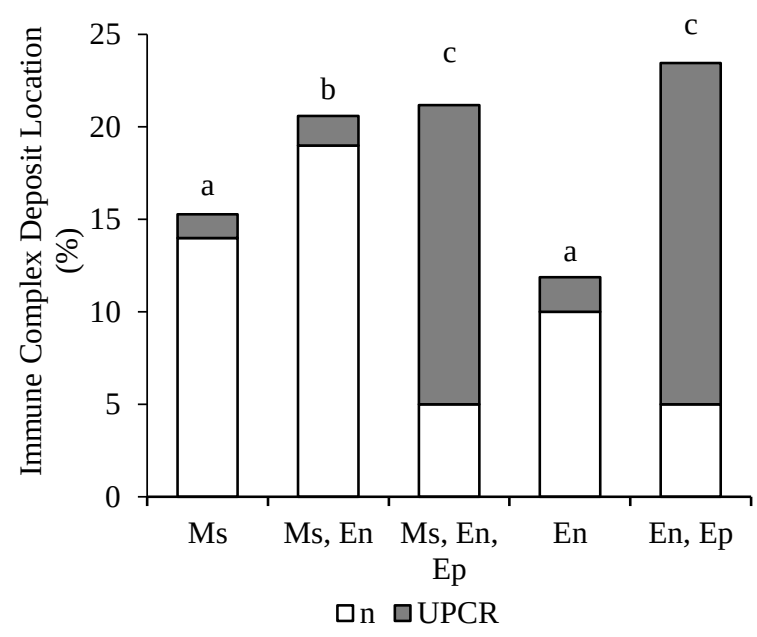

Figure 2. Differences between Immune Complex Deposit Location Group and Urine Protein/Creatinine Ratio. The different letter indicated the significantly differences between groups based on Mann-Whitney test. Note: Ms = Mesangial; En = Endothelial; Ep =Epithelial; UPCR = Urine Protein/creatinine ratio; Proteinuria was measured using dipstick test; ${ }^{*} \mathrm{p}<0.05$

the Kruskal-Wallis test was used to find out the differences in the urine protein/creatinine ratio in various location groups, with results that were sig- 
Table 2. Differences between Anti-dsDNA level and proteinuria

\begin{tabular}{|c|c|c|c|c|c|c|c|c|c|}
\hline \multirow{3}{*}{$\begin{array}{c}\text { Anti-dsDNA Level } \\
(\mathrm{IU} / \mathrm{mL})\end{array}$} & \multicolumn{8}{|c|}{ Proteinuria $(n=53)$} & \multirow{3}{*}{$P$ value } \\
\hline & \multicolumn{2}{|c|}{ Negative } & \multicolumn{2}{|c|}{$1+$} & \multicolumn{2}{|c|}{$2+$} & \multicolumn{2}{|c|}{$3+$} & \\
\hline & $\mathrm{N}$ & $\%$ & $\mathrm{n}$ & $\%$ & $\mathrm{~N}$ & $\%$ & $\mathrm{~N}$ & $\%$ & \\
\hline$<60$ & 10 & 18.9 & 2 & 3.8 & 4 & 7.5 & 4 & 7.5 & \\
\hline $61-200$ & 6 & 11.3 & 3 & 5.7 & 3 & 5.7 & 6 & 11.3 & 0.082 \\
\hline$>200$ & 1 & 1.9 & 2 & 3.8 & 7 & 13.2 & 5 & 9.4 & \\
\hline Total & 17 & 32.1 & 7 & 13.2 & 14 & 26.4 & 15 & 28.3 & \\
\hline
\end{tabular}

Note: Proteinuria was measured using dipstick method; Anti-dsDNA= Anti Double Stranded Deoxyribonucleic Acid; IU= International Unit.

nificantly different $(\mathrm{p}<0.05)$. Interestingly, the data showed that higher protein/creatine ratio tends to have antibody complex deposit in epithelial. It was observed that several immune complex deposit locations were associated with high protein/creatine ratio (Figure 2).

Mann Whitney post hoc analysis in various groups showed a significant difference in urine protein/creatinine ratio for the mesangial group compared to the mesangial, endothelial, epithelial group and the endothelial, epithelial group, each with a $p$ value of 0.005 , for the mesangial, endothelial group towards the mesangial, endothelial, epithelial group and the endothelial, epithelial group (both $p=0.021$ ) and for the endothelial group towards the mesangial, endothelial, epithelial group $(p=0.027)$ and the endothelial, epithelial group $(p=0.020)$ (Figure 2). This indicated that the immune complex deposit location group that contained the same distribution as the epithelium tends to represent heavy proteinuria.

The assessment of severity of proteinuria with the dye strip test measurement analysis among immune complex deposit locations tends to be less accurate than the protein: creatinine urine ratio. This is due to the proteinuria dye strip test is influenced by physical activity $[24,30]$. The use of the protein/creatinine ratio in urine has been recommended by the ACR criteria for kidney, which correlates well with 24-hour urine results. A protein: creatinine urine ratio $>0.5$ can replace the proteinuria dye strip test result of $>3+[24,25]$. Iriane stated that the protein: creatinine urine ratio had a sensitivity (82.05\%) and specificity (84.00\%) which is good for LN [31].

SLE diseases include soluble immune complex diseases; the clinical features are quite extensive and involve many organs of the body. Interactions between environmental, genetic and hor- monal factors in susceptible individuals generates an immune response that is abnormal, which with a loss of activity suppressor, causes the disruption of regulation and ineffective inhibition of CD4+ and CD8+ T-cells, and the decreased clearance of apoptotic cells and immune complexes. That process can trigger a loss of self-tolerance and lead to the formation of autoantibodies deposited as immune complexes in various body organs [3].

One serious manifestation of SLE is LN which is related to the production of nephritogenic autoantibodies. In general, the clinical feature of $\mathrm{LN}$ is a glomerular injury that occurs depending on the location of the immune complex deposits, as this determines the predominant glomerular cell type that is affected [32]. The immunopathology of the glomerulus begins from intraglomerular complement activation via the classical or alternative complement pathways. Immune complexes can be formed in many different compartments of the glomerulus, thereby determining the histopathological lesions. Different glomerular cell types primarily undergo activation in each compartment. Histopathological features determine the classification of glomerulonephritis. Immune complex deposits in mesangial and endothelial regions will activate mesangial and endothelial cells, causing mesangioproliferative glomerulopathy features [32], active urine sediment, and proteinuria, and is often accompanied by a decrease in kidney function. This is because the immune complex deposits were located proximal to the glomerular basement membrane, meaning that they also have access to vessels [9, 11]. Immune complex deposits in epithelial cells primarily activate glomerular visceral epithelial cells known as Podosit and usually cause massive proteinuria. These cells are important as they act as the glomerular filtration barrier. Podocytes loss causes progressive membranous neph- 
ronpathy and ESRD, as a result of the slow regeneration process of podocytes when compared to other cells. Primary membranous nephropathy evolved from autoimmunity against PLA2R, while secondary nephropathy is derived from a systemic disease that manifests as LN kidney. Therefore, proteinuria is an important prognostic and predictive marker of glomerulopathy [32].

Some studies have reported cases of mesangial LN with heavy proteinuria and followed disease progression [10, 12, 33]. Immune deposits in the mesangial region usually cause early signs of renal involvement with mild symptoms, including in LN class II. However, the reported cases experienced heavy proteinuria and active urine sediment [10, 33]. The pathogenesis is still unclear, but there is an idea that the immune complex deposits in the mesangial region would alter the glomerular permeability [10, 33]. Han et al. found that there is no correlation between immune complex deposits in the epithelium and proteinuria. There is no difference between patients with nephrotic and non-nephrotic histology. Nephrotic syndrome is said to be well correlated with podocytopathy than deposits in the epithelial, mesangial or mesangial cells [12].

The results of this study showed that there was no tendency towards severe proteinuria in the group where immune deposits are found in the epithelium, encompassing the mesangial, endothelial, epithelial group and the endothelial, epithelium group.

\section{Anti-dsDNA level with proteinuria}

The normality of anti-dsDNA level data was tested using the Kolmogorov-Smirnov test with $\mathrm{p}$ $<0.05$. These data did not have a normal distribution, even though data transformation had been done; thus, the Kruskal-Wallis test was used to assess the difference between different proteinuria severity level among different anti-dsDNA level groups, which showed no significant difference (p $=0.082$ ) (Table 2).

Difference tests among different urine protein /creatinine ratios with different levels of antidsDNA level used the Kruskal-Wallis test and showed a significant difference. Mann Whitney post hoc analysis in several anti-dsDNA level groups showed a significant urine protein/creatinine difference, which was found in the groups with an anti-dsDNA level of $<60$ and an anti-

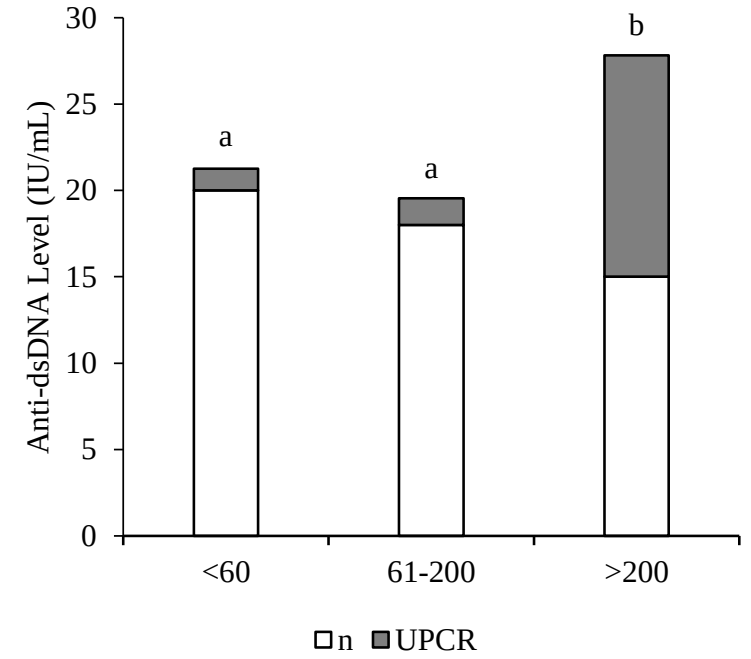

Figure 3. The Differences of anti-dsDNA level to urine protein/creatinine ratio. The different letter indicated the significantly differences between groups based on Mann-Whitney test. Notes: UPCR = Urine Protein/creatinine ratio; Anti-dsDNA $=$ Anti Double Stranded Deoxyribonucleic Acid; IU= International Unit; *p $<0.05$

dsDNA level of $>200 \mathrm{IU} / \mathrm{mL}$ ( $\mathrm{p}=0.018$ ), and the group with an anti-dsDNA level of $61-200$ $\mathrm{IU} / \mathrm{mL}$ and an anti-dsDNA level of $>200 \mathrm{IU} / \mathrm{mL}$ $(p=0.014)$. Higher protein/creatine ratio level was mainly observed in the high anti-dsDNA level (Figure 3). This suggests that high levels of antidsDNA tend to cause heavy proteinuria.

Results of Spearman correlation test found a significant association between anti-dsDNA level and the severity of proteinuria, measured by the dye strip check $(p=0.017)$ and protein: creatinine urine ratio $(p=0.040)$ with a correlation strength of 0.326 and 0.284 , respectively. Anti-dsDNA antibodies had a high sensitivity and specificity for the diagnosis of SLE and correlated with disease activity, especially for patients with nephritis [14]. Research conducted by Moroni et al., including $107 \mathrm{LN}$ patients, suggested that patients with high anti-dsDNA levels experienced significantly higher proteinuria [17].

A study by Linnik et al., of 487 patients with SLE and LN, stated that a history of anti-dsDNA levels that were higher than normal indicated changes in anti-dsDNA levels which were directly related to the risk of a renal flare-up [34]. Proper treatment to reduce anti-dsDNA levels in patients with LN may help to reduce the risk of kidney 
damage and result in a better prognosis than in patients with higher and more stable levels of antidsDNA [3]. The results of this study also showed a correlation between anti-dsDNA levels and the severity of proteinuria in LN patients, which is expected due to the administration of appropriate therapy that can reduce anti-dsDNA levels and proteinuria.

This study split the anti-dsDNA level into 3 groups: < $60 \mathrm{IU} / \mathrm{mL}$ (low positive), 61 to $<200$ $\mathrm{IU} / \mathrm{mL}$ (positive) and $>200 \mathrm{IU} / \mathrm{mL}$ (high positive). The comparison between every anti-dsDNA level and every proteinuria severity level was performed using the dye strip test, giving results that were not significant, while the comparison of the protein : urine creatinine ratio was significant ( $\mathrm{p}<$ 0.05 ). This could be because the dye strip proteinuria tests were less accurate and influenced by many factors such as those previously described; the sample amount was not significantly different between groups.

The dsDNA antibody is specific for SLE [35] and plays a role in the pathogenesis of organ manifestations, especially in the kidneys, where glomerulonephritis can occur [15]. Some factors that play a role in the pathogenicity of anti-dsDNA antibodies are IgG isotype and the ability to improve the compliment, capacity, and affinity of dsDNA [34]. Proteinuria is one of the clinical manifestations that reflects disease activity in LN [36]. Animal studies by Fenton et al. stated that the production of anti-dsDNA antibodies appears as immune complexes and excessive deposition in the kidneys, causing proteinuria [37]. Another study reported that anti-dsDNA antibodies have also been found in the glomerulus of active LN patients, and differences in histopathological features were caused by differences in the location of the immune complex deposits in the glomerulus [14]. Mechanisms can involve direct or indirect binding to the antigen, such as via extracellular matrix components and/or renal cells in the glomerulus, or cross-reactions with chromatin components, triggering cellular activation and cellular proliferation, resulting in inflammation and fibrosis [36].

\section{Conclusion}

This study shows that the severity of proteinuria in LN is determined by the location of immune complex deposits in kidneys and antidsDNA antibody levels. However, this study has limitations, as it uses only one type of immunofluorescent staining antibody and the relatively low sample quantity. Another factor that may limit this study is the medical intervention to LN may suppress the flare (proteinuria and dsDNA level) in the system, as patient's medical record is not included. Therefore, it is expected that further research can combine this with other antibodies, to provide better explanations about immune complex deposits in LN.

\section{Acknowledgment}

The author thanks Brawijaya University and Saiful Anwar Public Hospital Malang for supporting this research.

\section{References}

1. Isbagio H, Kasjmir Y, Setyohadi B, Suarjana N (2009) Lupus eritematosus sistemik. In: Sudoyo A, Setiyohadi B, Alwi I et al., eds. Buku ajar ilmu penyakit dalam. Jakarta, Interna Publishing. pp 2565 - 2579.

2. Bagavant H, Fu SM (2009) Pathogenesis of kidney disease in systemic lupus erythematosus. Current Opinion in Rheumatology 21 (5): 489 - 494. doi: 10.1097/BOR.0b013e32832efff1.

3. Rahman A, Isenberg DA (2008) Systemic lupus erythematosus. The New England Journal of Medicine 358 (9): 929 - 939. doi: 10.1056/NEJMra071297.

4. Danchenko N, Satia JA, Anthony MS (2006) Epidemiology of systemic lupus erythematosus: a comparison of worldwide disease burden. Lupus 15 (5): 308 - 318. doi: 10.1191/0961203306lu2305xx.

5. Kasjmir YI, Handono K, Wijaya LK et al. (2011) Rekomendasi perhimpunan reumatologi Indonesia untuk diagnosis dan pengelolaan lupus eritematosus sistemik. Jakarta, Perhimpunan Reumatologi Indonesia.

6. Contreras G, Pardo V, Cely C et al. (2005) Factors associated with poor outcomes in patients with lupus nephritis. Lupus 14 (11): 890 - 895. doi: 10.1191/0961203305lu2238oa.

7. Beck L, Bomback AS, Choi MJ et al. (2013) KDOQI US commentary on the 2012 KDIGO Clinical practice guideline for glomerulonephritis. American Journal of Kidney Diseases 62 (3): 403 - 441. doi: 10.1053/j.ajkd.2013.06.002.

8. Handono K (2010) Peran polimorfisme gen interferon-g (IFNG) pada fenotip histologi nefritis lupus. Indonesian Journal of Clinical Pathology and Medical Laboratory 17 (1): 38 - 43.

9. Bawazier L, Dharmeizar, Markum H (2009) Nefritis lupus. In: Sudoyo A, Setiyohadi B, Alwi I, et al., eds. Buku ajar ilmu penyakit dalam. Jakarta, Interna Publishing. pp 983 - 991.

10. Stankeviciute N, Jao W, Bakir A, Lash JP (1997) Mesangial lupus nephritis with the associated nephrotic syndrome. Journal of the American Society of Nephrology 8 (7): 1199 - 1204. 
11. Weening JJ, D'Agati VD, Schwartz MM et al. (2004) The classification of glomerulonephritis in systemic lupus erythematosus revisited. Journal of the American Society Nephrology 15 (2): 241 - 250. doi: 10.1097/01.asn.0000108969.21691.5d.

12. Han TS, Schwartz MM, Lewis EJ (2006) Association of glomerular podocytopathy and nephrotic proteinuria in mesangia lupus nephritis. Lupus 15 (2): 71 - 75. doi: 10.1191/09612033 06lu2264oa.

13. Cozzani E, Drosera M, Gasparini G, Parodi A (2014) Serology of lupus erythematosus: Correlation between immunopathological features and clinical aspects. Autoimmune Diseases 2014 1 - 13. doi: 10.1155/2014/321359.

14. Waldman M, Madaio M (2005) Pathogenic autoantibodies in lupus nephritis. Lupus 14 (1): 19 - 24. doi: 10.1191/09612033 05lu2054oa.

15. Villalta D, Bizzaro N, Bassi N et al. (2013) Anti-dsDNA antibody isotypes in systemic lupus erythematosus: IgA in Addition to IgG Anti-dsDNA help to identify glomerulonephritis and active disease. PLoS ONE 8 (8): e71458. doi: 10.1371/journal.pone.0071458.

16. D'Agati VD, Appel GB (2007) Lupus nephritis: Pathology and pathogenesis. In: Wallace DJ, Hahn BH, eds. Duboi's lupus erythematosus. 7th ed. Philadelphia, Lippincott William and Wilkins. pp $1094-1111$.

17. Yung S, Chan TM (2008) Anti-DNA antibodies in the pathogenesis of lupus nephritis-the emerging mechanisms. Autoimmunity Reviews 7 (4): 317 - 321. doi: 10.1016/j.autrev.2007.12. 001.

18. Moroni G, Quaglini S, Radice A et al. (2015) The value of a panel of autoantibodies for predicting the activity of lupus nephritis at time of renal biopsy. Journal of Immunology Research 2015: 1 - 8. doi: 10.1155/2015/106904.

19. Xuejing Z, Jiazhen T, Jun L et al. (2012) Urinary TWEAK level as a marker of lupus nephritis activity in 46 cases. Journal of Biomedicine and Biotechnology 2012: 1 - 7. doi: 10.1155/2012/ 359647.

20. KDIGO (2013) KDIGO clinical practice guideline for the evaluation and management of chronic kidney disease. Kidney International Supplements 3 (1).

21. Price CP, Newall RG, Boyd JC (2005) Use of protein: Creatinine ratio measurements on random urine samples for prediction of significant proteinuria: A systematic review. Clinical Chemistry 51 (9): 1577 - 1586. doi: 10.1373/clinchem.2005.049742.

22. Dahlan S (2010) Besar sampel dan cara pengambilan sampel dalam penelitian kedokteran dan kesehatan. Jakarta, Penerbit Salemba Medika.

23. Bancroft JD, Gamble M (2008) Theory and practice of histological techniques. Amsterdam, Elsevier Health Sciences. pp 105 121.
24. Dooley M, Aranow C, Ginzler E (2004) Review of ACR renal criteria in systemic lupus erythematosus. Lupus.; 13(11):85760. doi: 10.1191/0961203304lu2023oa.

25. Bevra HH, Maureen M, Alan W et al. (2012) American College of Rheumatology guidelines for screening, case definition, treatment and management of lupus nephritis. Arthritis Care and Research 64 (6): 797 - 808. doi: 10.1002/acr.21664.

26. Miller FW, Cooper GS (2007) The environmental aspect of lupus. In: Wallace DJ, Hahn BH Eds. Duboi's lupus erythematosus. 7th ed. Philadelphia, Lippincott William and Wilkins. pp 21 $-27$.

27. Walker SE (2007) The importance of sex hormones in systemic lupus erythematosus. In: Wallace DJ, Hahn BH Eds. Duboi's lupus erythematosus. 7th ed. Philadelphia, Lippincott William and Wilkins. pp $273-281$.

28. Rus V, Maury EE, Hochberg MC (2007) The epidemiology of systemic lupus erythematosus. In: Wallace DJ, Hahn BH Eds. Duboi's lupus erythematosus. 7th ed. Philadelphia, Lippincott William and Wilkins. pp $34-42$.

29. Tsokos GC (2011) Systemic lupus erythematosus. The New England Journal of Medicine 365 (22): 2110 - 2121. doi: 10.1056/NEJMra1100359.

30. National Kidney Foundation (2002) K/DOQI clinical practice guidelines for chronic kidney disease: Evaluation, classification, and stratification. American Journal of Kidney Diseases 39 (2 Suppl 1): 1 - 266.

31. Iriane VM (2015) Analisis kadar transforming growth factor beta 1 Urine (uTGF-B1) dan rasio protein/kreatinin urine sebagai petanda biologi diagnosis nefritis lupus. Doctoral Thesis. Universitas Brawijaya

32. Kurts C, Panzer U, Anders HJ, Rees AJ (2013) The immune system and kidney disease: basic concepts and clinical implications. Nature Reviews Immunology 13 (10): 738 - 753. doi: 10.1038/nri3523.

33. Su CF, Chen YC, Chen HH et al. (1997) Mesangial lupus nephritis (WHO Class II) with associated nephritic syndrome: A case report and review the literature.

34. Linnik MD, Hu JZ, Heilbrunn KR et al. (2005) Relationship between anti-double-stranded DNA antibodies and exacerbation of renal disease in patients with systemic lupus erythematosus. Arthritis and Rheumatology 52 (4): 1129 - 1137. doi: 10.1002/art.20980.

35. Arbuckle MR, McClain MT, Rubertone MV et al. (2003) Development of autoantibodies before the clinical onset of systemic lupus erythematosus. The New England Journal of Medicine 349 (16): 1526 - 1533. doi: 10.1056/NEJMoa021933.

36. Yung S, Chan TM (2015) Mechanisms of kidney injury in lupus nephritis - the role of anti-dsDNA Antibodies. Frontiers in Immunology 6: 475. doi: 10.3389/fimmu.2015.00475. eCollection 2015. 
KA Engli, K Handono, MH Eko et al., 2018 / Anti-dsDNA and Immune Complex are Associated with Proteinuria

37. Fenton K, Fismen S, Hedberg A et al. (2009) Anti-dsDNA antibodies promote initiation and acquired loss of renal dnase1 promotes progression of lupus nephritis in autoimmune
(NZBxNZW)F1 Mice. PLoS ONE 4 (12): e8474. doi: 10.1371/journal.pone.0008474. 